Review

\title{
Importance of right heart catheterization in advanced heart failure management
}

\author{
John M. Cochran ${ }^{1, \dagger}$, Amit Alam ${ }^{1,2,3,4, \dagger}$, Cesar Y. Guerrero-Miranda ${ }^{1,2,3,4, *}$ \\ ${ }^{1}$ Department of Cardiology, Baylor University Medical Center, Dallas, TX 75246, USA, \\ ${ }^{2}$ Annette C. and Harold C. Simmons Transplant Institute, Baylor Scott \& White Research Institute, Dallas, TX 75204, USA \\ ${ }^{3}$ Center for Advanced Heart and Lung Disease, Baylor University Medical Center, Dallas, TX 75246, USA \\ ${ }^{4}$ Department of Internal Medicine, Texas A\&M Health Science Center, Bryan, TX 77807, USA \\ *Correspondence: Cesar.GuerreroMiranda@bswhealth.org (Cesar Y. Guerrero-Miranda) \\ $\dagger$ These authors contributed equally. \\ Academic Editor: Giuseppe Biondi-Zoccai \\ Submitted: 21 October 2021 Revised: 24 November 2021 Accepted: 6 December 2021 Published: 13 January 2022
}

\begin{abstract}
Patients with chronic congestive heart failure belong to a population with reduced quality of life, poor functional class, and increased risk of mortality and morbidity. In these patients, assessment of invasive hemodynamics both serves therapeutic purposes and is useful for stratification roles. The right heart catheterization has become a cornerstone diagnostic tool for patients in refractory heart failure or cardiogenic shock, as well as for the assessment of candidacy for heart replacement therapies, and the management of patients following mechanical circulatory assist device implantation and heart transplantation.
\end{abstract}

Keywords: Pulmonary artery catheter; Swan-Ganz catheter; Right heart catheterization; Invasive hemodynamics; Cardiogenic shock; Heart failure; Acute decompensated heart failure

\section{Introduction}

The history of right heart catheterization (RHC) began in 1929, when Dr. Werner Forssmann, as a surgical trainee in Germany, advanced a 4 French urinary tract catheter from the antecubital fossa to the right atrium and confirmed the position by fluoroscopy [1]. Decades later, Drs. Cournand and Richards won the Nobel Prize in medicine for describing the concept of invasive hemodynamics using RHC [2]. In 1970, a case series of 100 consecutive pulmonary catheterizations with the flow-directed catheter was published [3], validating modern-day RHC developed by Drs. Ganz and Swan [3] (Fig. 1). Since then, RHC has been utilized in many clinical scenarios and endorsed by many societal guidelines (Tables 1,2). It is the objective of this review to summarize the current understanding and indications of RHC.

\section{The role of right heart catheterization and invasive hemodynamic monitoring in patients with acute decompensated heart failure}

The utility of invasive hemodynamic evaluation via RHC in patients with acute decompensated heart failure is still under debate. Before the 1970s, an invasive hemodynamic assessment was essential in the diagnosis of structural heart disease [4]. In the late 1970s, however, significant advancements were made in echocardiography. Specifically, Doppler echocardiography permitted the estimation of pressure gradients across stenotic valves and of intracardiac chamber pressures with a good correlation be- tween invasive measurements and Doppler estimations in most circumstances [5,6]. The use of full Doppler echocardiographic examination has been proposed as a complete, viable replacement to RHC in stable patients with heart failure. Temporelli et al. [7] found an excellent correlation between Doppler echocardiographic results and direct hemodynamic values obtained from RHC. However, RHC remains a crucial tool in the hemodynamic evaluation due to known limitations of echocardiography. Right heart filling pressures are hampered in patients with mechanical ventilation, indwelling cardiac devices can generate artifacts, and patient habitus or dressings after cardiac surgery may make correct alignment of Doppler waveforms impossible and hemodynamic calculations inaccurate. Complex hemodynamic scenarios with multiple high-velocity jets can also render isolating the correct waveform challenging. Furthermore, continuous echocardiography over hours and days to provide real-time hemodynamic data in response to interventions is not feasible in the same manner that continuous hemodynamic monitoring with RHC is feasible.

Despite the advances in technology, physical examination remains crucial in the management of heart failure patients. Thus, it is important to recognize the strengths and limitations of the clinical examination in these patients. In general, the ability to estimate congestion by physical examination is superior to the recognition of an inadequate perfusion status [8]. The physical examination is accurate in the assessment of elevated cardiac filling pressures in only $60-70 \%$ of cases, mostly due to elevation in jugular ve- 


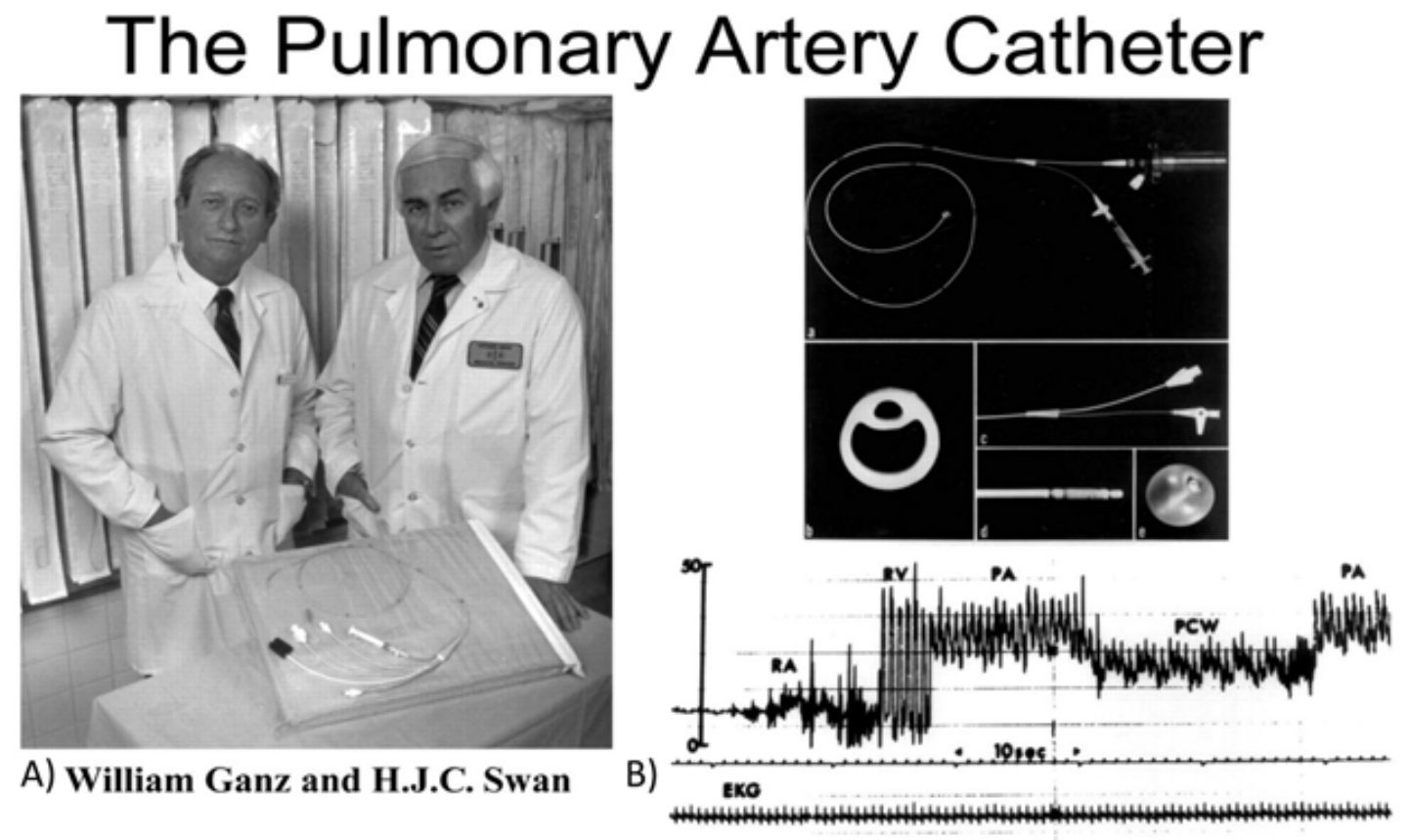

Fig. 1. The development of the pulmonary artery catheter. (A) Drs. Swan and Ganz. (B) Swan-Ganz catheter and waveforms generated after floated from the right atrium to the pulmonary arteries. (Figure courtesy of Dr. Peter Ganz, San Francisco General Hospital, University of California, San Francisco).

nous pressure [9]. Drazner et al. [10] demonstrated a concordant relationship between elevated right atrial pressure and pulmonary capillary wedge pressure in approximately $80 \%$ of patients with decompensated heart failure. Thus, the role of RHC in the clinical scenarios of a patient with elevated right-side pressures that are not correlated with elevated left-sided filling pressures (e.g., in patients with advanced lung disease and pulmonary hypertension), remains invaluable.

The widespread use of RHC has been called into question by some clinicians, primarily because of the Evaluation Study of Congestive Heart Failure and Pulmonary Artery Catheterization Effectiveness (ESCAPE) trial [11]. That randomized controlled study included nearly 400 patients with heart failure comparing RHC to clinical assessment alone. The study excluded patients for whom RHC may have been warranted by significant renal dysfunction (serum creatinine $>3.5 \mathrm{mg} / \mathrm{dL}$ ), prior use of moderate dose inotropes, or pulmonary hypertension. In addition, the ESCAPE trial did not study patients with cardiogenic shock in whom inotropic and vasopressor therapy is frequently used. The study concluded that the use of RHC did not demonstrate a mortality benefit or shorter hospitalization in stable, hospitalized patients. Therefore, the use of RHC should be restricted to complex and severe cases.

The American College of Cardiology Foundation (ACCF)/American Heart Association (AHA) [12] and European Society of Cardiology (ESC) [13] guidelines for the management of heart failure outline the clinical conditions in which the use of RHC should be considered (Table 1).
The guidelines emphasize that RHC is not routinely recommended for all patients with decompensated heart failure. Rather, invasive hemodynamic monitoring should be considered in patients with decompensated heart failure refractory to the initial therapy, for patients with unclear volume status and ongoing hypoperfusion, or patients being considered for advanced therapies.

\section{The role for invasive hemodynamic monitoring in patients with cardiogenic shock}

Cardiogenic shock (CS) is the most severe form of heart failure with significant mortality and morbidity [14]. $\mathrm{CS}$ is a consequence of myocardial muscle dysfunction either due to ischemic or non-ischemic culprit event, manifested by detrimental organ perfusion and could progress into multiorgan failure.

$\mathrm{CS}$, defined by clinical presentation and invasive hemodynamic criteria, is characterized by a state of tissue hypoperfusion secondary to inadequate cardiac output (CO) in the absence of hypovolemia [15] (Table 3). Within this context, the utility of RHC in the diagnosis, staging, phenotyping, and monitoring of patients in CS is invaluable, especially in the presence of complex hemodynamic interplays such as valvular disease and/or pulmonary hypertension. In 2019, the Society for Cardiovascular Angiography and Interventions released a consensus statement on the classification of $\mathrm{CS}$, which stratifies patients in five stages (A through $\mathrm{E}$ in ascending levels of severity) (Table 4, Ref. [15]). While physical exam findings and labo- 
Table 1. Right heart catheterization recommendations. 2013 ACCF/AHA and 2021 ESC HF management guidelines.

\begin{tabular}{|c|c|c|c|}
\hline & Recommendations & $\mathrm{COI}$ & $\mathrm{LOE}$ \\
\hline \multirow{3}{*}{$\begin{array}{l}2013 \text { ACCF/AHA HF } \\
\text { Management Guideline }\end{array}$} & $\begin{array}{l}\text { Invasive hemodynamic monitoring is recommended in patients with respiratory distress or impaired systemic perfusion } \\
\text { when clinical assessment is inadequate }\end{array}$ & I & $\mathrm{C}$ \\
\hline & $\begin{array}{l}\text { Invasive hemodynamic should be considered for carefully selected patients with acute HF with persistent symptoms } \\
\text { and/or when hemodynamics are uncertain }\end{array}$ & IIa & $\mathrm{C}$ \\
\hline & Routine use of invasive hemodynamic monitoring is not recommended in normotensive patients with acute HF & III & B \\
\hline \multirow{4}{*}{$\begin{array}{l}2021 \text { ESC HF } \\
\text { Management Guideline }\end{array}$} & Right heart catheterization is recommended in patients with severe HF being evaluated for heart transplantation or MCS & I & $\mathrm{C}$ \\
\hline & $\begin{array}{l}\text { Right heart catheterization should be considered in patients where HF is thought to be due to constrictive pericarditis, } \\
\text { restrictive cardiomyopathy, congenital heart disease, and high output states. }\end{array}$ & IIa & $\mathrm{C}$ \\
\hline & $\begin{array}{l}\text { Right heart catheterization should be considered in patients with probable pulmonary hypertension, assessed by echo } \\
\text { in order to confirm the diagnosis and assess its reversibility before the correction of valve/structural heart disease. }\end{array}$ & IIa & $\mathrm{C}$ \\
\hline & Right heart catheterization may be considered in selected patients with HFpEF to confirm the diagnosis. & $\mathrm{IIb}$ & $\mathrm{C}$ \\
\hline
\end{tabular}

COR, Class of Recommendation; LOE, level of Evidence; HF, Heart Failure; MCS, Mechanical Circulatory Support; HFpEF, Heart Failure with Preserved Ejection Fraction; ACC, American College of Cardiology; AHA, American Heart Association; ESC, European Society of Cardiology.

Table 2. Overview of applications of right heart catheterization in advanced heart failure patients.

\begin{tabular}{|c|c|c|}
\hline Clinical scenario & Important applications & $\begin{array}{l}\text { Key/Unique measurements and } \\
\text { calculations }\end{array}$ \\
\hline Acute decompensated heart failure & $\begin{array}{l}\text { Evaluation of volume status and output state, especially when clinical } \\
\text { exam/echo is equivocal }\end{array}$ & CVP, PCWP, CO, CI \\
\hline Cardiogenic shock & $\begin{array}{l}\text { Diagnosis, risk stratification, real-time titration of pharmacological va- } \\
\text { soactive medications, decision support for implantation/titration/weaning of } \\
\text { MCS }\end{array}$ & CVP, PCWP, CO, CI \\
\hline Evaluation for OHT/VAD & $\begin{array}{l}\text { INTERMACS profiling, standard hemodynamic measurements, and titra- } \\
\text { tions as above }\end{array}$ & CVP, PCWP, CO, CI \\
\hline Evaluation after OHT/VAD & $\begin{array}{l}\text { Titration of vasoactive medications, necessary for biopsy, evaluate for RH } \\
\text { failure, predict mortality }\end{array}$ & $\begin{array}{l}\text { Endomyocardial biopsy (post- } \\
\text { transplantation) }\end{array}$ \\
\hline $\begin{array}{l}\text { Evaluation of concomitant pulmonary } \\
\text { hypertension }\end{array}$ & $\begin{array}{l}\text { The gold standard for PH diagnosis, important to assess response to therapy, } \\
\text { delineate into pre-/post-capillary (or mixed) profile }\end{array}$ & $\begin{array}{l}\text { mPA, PVR, PCWP, response to } \\
\text { vasodilator challenge }\end{array}$ \\
\hline Evaluation of right heart failure & $\begin{array}{l}\text { Post-surgery (including OHT or VAD), in the setting of pulmonary hyper- } \\
\text { tension or significant valvular disease, identifying isolated RHF }\end{array}$ & PAPI, CVP, PVR, RVSWI \\
\hline
\end{tabular}

ratory biomarkers figure into the schematic, invasive hemodynamic parameters from RHC become a crucial addition to the assessment, especially at the more advanced (C-E) stages of CS (Table 5).

The classical CS invasive hemodynamic profiling is "cold and wet" when low $\mathrm{CO}$ is associated with and with elevated systemic vascular resistance (SVR), however, there are several other CS profiling we recognized only with the use of invasive hemodynamic assessment (Table 6, Ref. [14]). Other less frequent subtypes of CS are normotensive and right ventricular (RV) CS. Normotensive CS patients have falsely 'normal' systemic blood pressure due to an elevated SVR but in the presence of low CO. In a post-MI CS registry of over 1000 patients, $5 \%$ of those had evidence of hypoperfusion with a systolic blood pressure of more than $90 \mathrm{mmHg}$ [16]. RV shock is present in approximately $5 \%$ of patients with post-myocardial infarction CS. Several in- vasive hemodynamic calculations can be crucial in the determination of right ventricular (RV) versus left ventricular (LV) CS: right atrial pressure (RAP) more than $15 \mathrm{mmHg}$ (mostly validated in post $\mathrm{LV}$ assist device (LVAD) patients), the ratio of the RAP and PCWP more than 0.8, pulmonary artery pulsatility index (PAPI) lower than 1.0, and RV stroke work index (RVSWI) $<600 \mathrm{mmHg} \times \mathrm{mL} / \mathrm{m}^{2}$ are present in RV failure $[17,18]$.

Cardiac power output (CPO) calculated as mean arterial pressure multiplied by $\mathrm{CO}$ and divided by 451 is a strong parameter to assess LV systolic function, especially for patients with chronic systolic heart failure with acute decompensation and a strong predictor of morbidity and mortality [19]. 
Table 3. 2015 SCAI/ACC/HFSA/STS definition of cardiogenic shock.

\begin{tabular}{|c|c|}
\hline \multirow{2}{*}{ Blood pressure criteria } & $\mathrm{SBP}<90 \mathrm{mmHg}$ for $>30 \mathrm{~min}$, or the need for supportive measures to maintain an SBP $>$ or $=90 \mathrm{mmHg}$ \\
\hline & Decrease in MAP > $30 \mathrm{mmHg}$ below baseline \\
\hline \multirow{2}{*}{ Hemodynamic criteria } & $\mathrm{CI}<$ or $=1.8 \mathrm{~L} / \mathrm{min} / \mathrm{m}^{2}$ without support or $<2.2 \mathrm{~L} / \mathrm{min} / \mathrm{m}^{2}$ with support \\
\hline & $\mathrm{PCWP}>$ or $=15 \mathrm{mmHg}$ \\
\hline
\end{tabular}

Table 4. The SCAI stages classification of cardiogenic shock (adapted from Baran et al. [15]).

\begin{tabular}{ll}
\hline Stage/Name & Description \\
\hline A "At risk" & The patient is not currently experiencing signs or symptoms of CS but is at risk (i.e., MI, CHF) \\
B "Beginning CS" & The patient has clinical evidence of relative hypotension without hypoperfusion \\
C "Classic CS" & The patient manifests with hypoperfusion that requires intervention (inotrope/pressor or MCS) beyond \\
& volume resuscitation to restore perfusion \\
D "Deteriorating/Doom" & The patient is like category C but is getting worse and failing to respond to initial interventions \\
E "Extremis" & The patient has circulatory collapse, frequent refractory cardiac arrest with ongoing CPR, or is being \\
& supported by multiple simultaneous acute interventions including ECPR \\
\hline
\end{tabular}

Modifier A: cardiac arrest - the presence of cardiac arrest, at any stage, would be considered a subtype (i.e., $\left.\mathrm{B}_{A}, \mathrm{C}_{A}, \mathrm{D}_{A}, \mathrm{E}_{A}\right)$

$\mathrm{CS}$, cardiogenic shock; MI, myocardial infarction; CHF, congestive heart failure; MCS, mechanical circulatory support; CPR,

cardiopulmonary resuscitation; ECPR, extracorporeal membrane oxygenation-facilitated CPR; SCAI, Society for Cardiovascular

Angiography and Interventions.

Table 5. Hemodynamic criteria associated with each stage of cardiogenic shock.

\begin{tabular}{ll}
\hline SCAI shock stage & Hemodynamic criteria \\
\hline A & Normotensive and if hemodynamics done: $\mathrm{CI}>2.5, \mathrm{CVP}<10$, PA Sat $>54 \%$ \\
$\mathrm{~B}$ & $\mathrm{SBP}<90 \mathrm{mmHg}$, or MAP $<60$ or $>30 \mathrm{mmHg}$ drop in blood pressure. If hemodynamics done: CI $>2.2$, PA Sat \\
& $>65 \%$ \\
$\mathrm{C}$ & Drugs/devices used to maintain blood pressure above stage B values. Hemodynamic Criteria: $\mathrm{CI}<2.2, \mathrm{PCWP}>15$, \\
& RAP/PCWP $>0.8$, PAPI $<1.85, \mathrm{CPO}<0.6$ \\
$\mathrm{D}$ & Any of stage C parameters requiring multiple pressors or addition of mechanical circulatory support \\
$\mathrm{E}$ & Persistent hypotension and worsening hemodynamics despite maximal support
\end{tabular}

CI, cardiac index; CPO, cardiac power output; MAP, mean arterial pressure; PAPI, pulmonary artery pulsatility index; PA Sat, pulmonary artery saturation; PCWP, pulmonary capillary blood pressure; RAP, right atrial pressure; SBP, systolic blood pressure.

Table 6. Cardiogenic shock clinical phenotypes (adapted from van Diepen et al. [14]).

\begin{tabular}{|c|c|c|c|}
\hline & & \multicolumn{2}{|c|}{ Volume status } \\
\hline & & Wet & Dry \\
\hline Peripheral & \multirow{2}{*}{ Cold } & Classic CS (“Cold \& Wet") & Euvolemic CS (“Cold \& Dry”) \\
\hline \multirow{2}{*}{ Perfusion } & & High SVR, low CI, high PCWP & High SVR, low CI, low/normal PCPW \\
\hline & \multirow{2}{*}{ Warm } & Mixed CS (“Warm \& Wet") & Vasodilatory shock (no CS) \\
\hline Status & & Normal SVR, low CI, high PCWP & Low SVR, high CI, low PCWP \\
\hline
\end{tabular}

Table 7. Pulmonary hypertension hemodynamic definitions from 6th World Symposium on Pulmonary Hypertension.

\begin{tabular}{lccc}
\hline & $\begin{array}{c}\text { Isolated pre-capillary PH } \\
\text { (WHO groups 1, 3, 4, 5) }\end{array}$ & $\begin{array}{c}\text { Combined PH } \\
\text { (WHO group 2) }\end{array}$ & $\begin{array}{c}\text { Isolated post-capillary PH } \\
\text { (WHO group 2) }\end{array}$ \\
\hline PCWP (mmHg) & $<15$ & $>15$ & $>15$ \\
mPAP (mmHg) & $>20$ & $>20$ & $>20$ \\
PVR (WU) & $\geq 3$ & $\geq 3$ & $<3$ \\
\hline
\end{tabular}

Given the high mortality rate of CS, several institutions have begun deploying 'shock teams' to streamline the expedient diagnosis and management of CS patients. Ideally formed by an advanced heart failure, an interventional 
Table 8. Hemodynamic criteria for diagnosis of primary graft dysfunction.

\begin{tabular}{|c|c|c|}
\hline Classification of PGD & Severity of PGD & Hemodynamic criteria \\
\hline \multirow[t]{4}{*}{ Left ventricular PGD } & $\begin{array}{l}\text { Mild: one of the following criteria } \\
\text { must be met }\end{array}$ & $\begin{array}{l}\mathrm{RAP}>15 \mathrm{mmHg}, \mathrm{PCWP}>20 \mathrm{mmHg}, \mathrm{CI}<2.0 \mathrm{~L} / \mathrm{min} / \mathrm{m}^{2} \text { lasting more than one } \\
\text { hour requiring low dose inotropes }\end{array}$ \\
\hline & $\begin{array}{l}\text { Moderate PGD: must meet one cri- } \\
\text { terion from A and another from } \mathrm{B}\end{array}$ & $\begin{array}{l}\text { A. RAP }>15 \mathrm{mmHg}, \mathrm{PCWP}>20 \mathrm{mmHg}, \mathrm{CI}<2.0 \mathrm{~L} / \mathrm{min} / \mathrm{m}^{2} \text {, hypotension with } \\
\text { MAP }<70 \mathrm{mmHg} \text { (lasting more than one hour) }\end{array}$ \\
\hline & & B. High dose inotropes with an inotrope score $>10$ or newly placed IABP \\
\hline & Severe PGD & Dependence on left or biventricular mechanical support including \\
\hline \multirow[t]{3}{*}{ Right ventricular PGD } & $\begin{array}{l}\text { Diagnosis requires either both } \mathrm{A} \\
\text { and } \mathrm{B} \text { or } \mathrm{C} \text { alone }\end{array}$ & $\begin{array}{l}\text { A. Hemodynamics with RAP }>15 \mathrm{mmHg} \text {, PCWP }<15 \mathrm{mmHg} \text {, CI }<2.0 \\
\mathrm{~L} / \mathrm{min} / \mathrm{m}^{2}\end{array}$ \\
\hline & & B. TPG $<15 \mathrm{mmHg}$ and/or pulmonary artery systolic pressure $<50 \mathrm{mmHg}$ \\
\hline & & C. Need for RVAD \\
\hline
\end{tabular}

Table 9. Guidelines for right heart hemodynamic assessment following heart transplantation.

\begin{tabular}{|c|c|c|c|}
\hline \multicolumn{2}{|c|}{ Scenario } & \multirow{2}{*}{$\frac{\text { Class recommendation }}{\mathrm{I}}$} & \multirow{2}{*}{$\frac{\text { Evidence level }}{\mathrm{C}}$} \\
\hline 1. & Suggestion of worsening allograft function or concerns for rejection & & \\
\hline 2. & Consideration of heart re-transplantation & I & $\mathrm{C}$ \\
\hline 3. & Pulmonary hypertension management in heart transplant recipients & IIa & $\mathrm{B}$ \\
\hline 4. & At the time of surveillance cardiac biopsy in an asymptomatic patient $\leq 6$ months vs. $>6$ months & $\begin{array}{l}\mathrm{IIa} \text { ( } \leq 6 \text { months }) \\
\mathrm{IIb} \text { (>6 months })\end{array}$ & $\mathrm{C}$ \\
\hline 5. & Suspected tamponade related to endomyocardial biopsy or immunosuppression & $\mathrm{IIb}$ & $\mathrm{C}$ \\
\hline 6. & Persistent concerns for congestion or renal dysfunction to assess hemodynamics and filling pressures & $\mathrm{IIb}$ & $\mathrm{C}$ \\
\hline 7. & Concerns of allograft vasculopathy or restrictive physiology & $\mathrm{IIb}$ & $\mathrm{C}$ \\
\hline
\end{tabular}

Table 10. Important pulmonary hemodynamics to assess for heart re-transplant candidacy.

\begin{tabular}{lc}
\hline Hemodynamic parameter & Abnormal value \\
\hline Pulmonary vascular resistance & $>5$ wood units \\
\hline Indexed pulmonary & $>6$ \\
\hline Vascular resistance & $>16 \mathrm{mmHg}$ \\
\hline Transpulmonary gradient & $>60 \mathrm{mmHg}$ with any one of the above \\
\hline Pulmonary artery & \\
\hline Systolic pressure
\end{tabular}

cardiologist, intensivist, and cardiovascular surgeon, a cardiogenic shock would take time-sensitive decisions, execute a treatment and choose the most appropriate intervention depending on the patient's status in a multidisciplinary approach, from the escalation of vasoactive drugs to temporary mechanical circulatory support (TMCS) devices in the acute shock phase. Decided which patients might need escalation on therapy for potential recovery or advanced heart failure candidacy, like heart transplantation, needs to be taken into account. Tehrani et al. [20] published a framework for the design and implementation of shock teams and protocols for both post-acute myocardial infarction CS (AMI-CS) and acute or chronic non-ischemic CS (non-AMI-CS). RHC after suspected CS helps to stratify the need for escalation of shock therapy and earlier utiliza- tion of TMCS. Survival of CS at their institution increased from $47 \%$ to $77 \%$ after implementation of risk scores based on invasive hemodynamic parameters and other clinical markers, with a $39 \%$ absolute increase in survival. The authors also developed a multifaceted risk score for CS that included the CPO and PAPI for the 30-day risk of mortality [20]. Similarly, the National Cardiogenic Shock Initiative implemented an algorithm designed to address AMI-CS. This algorithm uses invasive hemodynamic assessment and has changed the paradigm from solely "door-to-balloon" to "door-to-support" with the placement of TMCS before coronary revascularization if the cardiac index (CI) is $<2.2$ $\mathrm{L} / \mathrm{min} / \mathrm{m}^{2}$ and $\mathrm{LV}$ end-diastolic pressure is $>15 \mathrm{mmHg}$ [21].

Invasive hemodynamic assessment remains essential in patients who are in CS when the etiology is unknown or not well clarified. Moreover, continuous hemodynamic monitoring of the response to therapeutic regimens may help guide medical therapy. Several observational studies have shown that "tuning up" the hemodynamics in circulatory shock patients (i.e., target a PCWP less or equal than $15 \mathrm{mmHg}$ and a RAP less or equal than $8 \mathrm{mmHg}$ while avoiding systemic hypotension and progressive renal insufficiency) has led to a significant change in the critical care management and is associated with improved outcomes [22]. 
Table 11. New definition of right ventricular failure following LVAD implantation.

\begin{tabular}{|c|c|}
\hline Type of right heart failure & Definition \\
\hline Early acute RHF & RVAD implanted at time of LVAD operation \\
\hline \multirow{5}{*}{ Early post-implant RHF } & i. RVAD implanted within thirty days after LVAD implantation \\
\hline & OR \\
\hline & $\begin{array}{l}\text { ii. Failure of wean from inotropic or vasopressor medications or inhaled nitric oxide within } \\
\text { fourteen days after LVAD implantation }\end{array}$ \\
\hline & OR \\
\hline & Initiating the above support within thirty days of implant for a minimum of fourteen days \\
\hline \multirow{3}{*}{ Late RHF } & i. Implantation of an RVAD after thirty days of LVAD implantation \\
\hline & OR \\
\hline & $\begin{array}{l}\text { ii. Any hospitalization greater than thirty days post LVAD implantation which requires in- } \\
\text { travenous diuretics or inotropic support for at least seventy two hours }\end{array}$ \\
\hline
\end{tabular}

Table 12. Signs of right heart failure following left ventricular assist device implantation.

\begin{tabular}{|c|c|c|}
\hline Criteria & Sig & \\
\hline \multirow{4}{*}{ Hemodynamic } & \multicolumn{2}{|c|}{ i. Elevated central venous pressure of at least $>16 \mathrm{mmHg}$} \\
\hline & & Mixed venous saturation $<50 \%$ \\
\hline & & Cardiac index $<2.2 \mathrm{~L} / \mathrm{min} / \mathrm{m}^{2}$ \\
\hline & iv. & Absence of cardiac tamponade and reduction in pump flow of $>30 \%$ from the previous baseline \\
\hline \multirow{3}{*}{ Physical exam } & \multicolumn{2}{|c|}{ i. Ascites } \\
\hline & ii. & Limiting edema \\
\hline & iii. & Increased central venous pressure at least halfway up the neck in an upright patient \\
\hline \multirow{3}{*}{ Signs of end organ dysfunction } & \multicolumn{2}{|c|}{ i. Renal failure with serum creatinine $>2 \times$ baseline value } \\
\hline & ii. & Liver injury with an elevation of at least $2 \times$ upper limit of normal in AST/ALT or total bilirubin $>2.0$ \\
\hline & & Lactate $>3.0 \mathrm{mmol} / \mathrm{L}$ \\
\hline
\end{tabular}

\section{The role for right heart catheterization in advanced heart failure therapy (stage D) and heart replacement therapy candidacy}

Invasive hemodynamic assessment is recommended by both American and European heart failure guidelines for the management of heart failure patients being considered for durable LV assist device (LVAD) or cardiac transplantation. In addition, to evaluate the reversibility of pulmonary hypertension, the use of RHC may have important prognostic implications and may help clinicians in their decision to implant an LVAD or to transplant [23]. For example, a study of 657 consecutive heart transplant recipients in Italy from 2000-2018 found that right heart failure (RHF) defined by low PAPI $(<1.68)$ was associated with the need for renal replacement therapy and primary graft dysfunction [24]. For both LVAD and transplant patients, in an analysis of the previously described ESCAPE trial, the authors found that an increased RAP/PCWP ratio was associated with adverse clinical outcomes [25].

Pulmonary hypertension occurs frequently in patients with heart failure and has important therapeutic and prognostic implications in both inpatient and outpatient management [26]. The gold standard for diagnosis and mon- itoring of pulmonary hypertension is right heart catheterization. With the publication of proceedings from the 2018 6th World Symposium on Pulmonary Hypertension, updated definitions and subtypes of pulmonary hypertension were elaborated. Most conspicuously, the threshold for mean pulmonary artery pressure was established at $20 \mathrm{mmHg}$ from the prior cutoff of $25 \mathrm{mmHg}$ [27]. The traditional classification into WHO groupings $1-5$ remained unchanged, with WHO group 2 defined as $\mathrm{PH}$ due to left heart disease. In addition to etiological groupings, the proceedings defined 3 different hemodynamic profiles: isolated pre-capillary pulmonary hypertension, combined pre-/post-capillary hypertension, and isolated postcapillary pulmonary hypertension [27] (Table 7). Of these profiles, combined pre-/post-capillary $\mathrm{PH}$ and isolated postcapillary $\mathrm{PH}$ are found in patients with left heart disease. Typically, a transpulmonary gradient (mPA-PCWP) greater than $12 \mathrm{mmHg}$ with a diastolic pulmonary gradient (diastolic PA pressure-PCWP) below $3 \mathrm{mmHg}$ is seen in these patients.

In addition to the standard collection of hemodynamic data, vasoreactivity testing and exercise testing are sometimes important in the evaluation of this patient population. For example, vasoreactivity testing (preferably with inhaled 
nitric oxide at 10-20 ppm) is performed in patients with PAH (WHO group $1 \mathrm{PH}$ ) wherein an absolute drop in $\mathrm{mPA}$ by $10 \mathrm{mmHg}$ to an absolute value of less than $40 \mathrm{mmHg}$ while maintaining cardiac output. In advanced HF patients with WHO group $2 \mathrm{PH}$ being considered for transplantation, vasoreactivity testing may be used to assess for fixed $\mathrm{PH}$ and prognosticate before transplantation [42]. Exercise testing or fluid challenge during RHC can also be used to unmask pulmonary hypertension in patients with borderline hemodynamic profiles [28].

Finally, precise diagnosis with meticulous attention to detail is crucial when evaluating the heart failure patient with $\mathrm{PH}$ for several reasons. Administration of therapies directed towards PAH (WHO group $1 \mathrm{PH}$ ) has met with mostly negative results including worsening of HF and increased mortality across a range of PAH therapies [26]. Furthermore, the degree, presence of, and vasoreactivity of $\mathrm{PH}$ in patients with advanced HF can have important prognostic consequences when considering the placement and adjustment of advanced therapies including temporary and durable mechanical circulatory support as well as transplantation.

\section{The role of invasive hemodynamic monitoring in post-heart replacement therapy management}

\subsection{The role of invasive hemodynamic monitoring in the management of primary graft dysfunction}

The leading cause of death among patients receiving heart transplantation is primary graft dysfunction (PGD) [29]. PGD is defined as LV and/or RV graft failure occurring in the immediate post-transplant period in the absence of an anatomic or immunologic etiology. Early and accurate diagnosis is therefore critical for optimizing outcomes [30]. All patients receiving heart transplantation leave the operating room to assess for PGD and to optimize hemodynamics. The severity of PGD is based on RHC criteria [31] (Table 8).

\subsection{The role of invasive hemodynamic monitoring in the long-term management of heart transplant recipients}

RHC plays an important prognostic role after cardiac transplantation. In the long-term management of heart transplant recipients, there are only two Class 1 recommendations that require $\mathrm{RHC}$, namely in the assessment of patients that may require heart re-transplantation and in patients who present with signs suggestive of allograft dysfunction (Table 9). The International Society for Heart and Lung Transplantation (ISHLT) position statement also includes Class 2 recommendations for RHC in the management of heart transplant recipients [32].

$\mathrm{RHC}$, in combination with an endomyocardial biopsy, can potentially differentiate patients who are hemodynamically stable from those patients with substantial allograft dysfunction and abnormal hemodynamics to further as- sist in therapeutic intervention. Patients without hemodynamic compromise in the setting of rejection can be treated with anti-rejection treatment. Those with compromised hemodynamics may require diuretics, pressors, and inotropic assistance (Fig. 2). Therefore, the need for an RHC in these scenarios is critical for prognostication, diagnosis, and management [32,33]. Additionally, RHC has a Class 1 recommendation for patients under consideration for heart re-transplantation [34]. For these patients, RHC is needed to assess for pulmonary vascular resistance, pulmonary artery pressures, and transpulmonary gradient [35] (Table 10). A patient who remains refractory to medical therapy regarding this specific hemodynamics may not be eligible for heart re-transplantation [35,36]. More importantly, patients with elevated pulmonary pressures are at a high risk of morbidity and mortality [37,38].

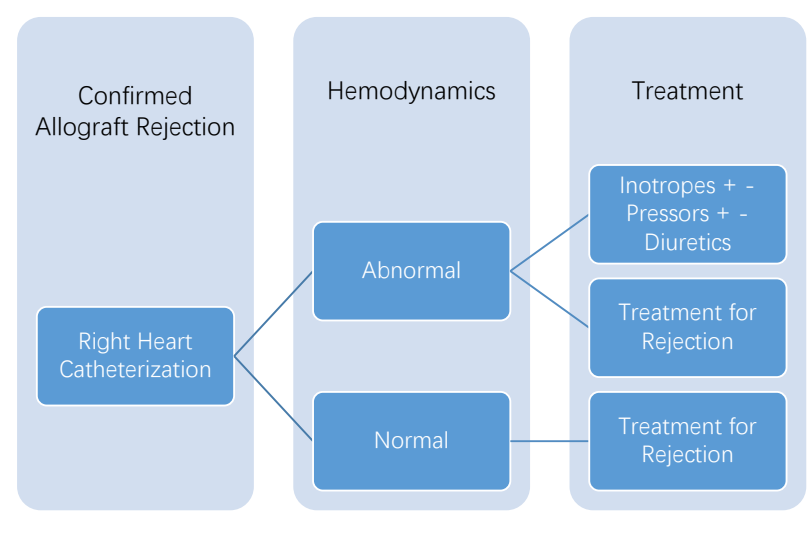

Fig. 2. Right heart catheterization guided treatment mechanism in the setting of rejection.

\subsection{The role of invasive hemodynamic monitoring in post-left ventricular assist device management}

In the past decade, the definition of RHF has varied across studies. As a result, estimates of RHF after LVAD implantation have varied from 3-40\% [39,40]. Additionally, the prior definition of RHF endorsed by the Society of Thoracic Surgeons Interagency Registry for Mechanically Assisted Circulatory Support (STS-INTERMACS) was complex and therefore challenging to apply [40]. As a result, outcomes for RHF following LVAD placement were not presented in the most recent 2020 STS-INTERMACS annual report $[36,41]$. The academic research consortium has since then attempted to simplify the definition while adding the timing from LVAD implantation and the need for chemical or mechanical RV support [39] (Table 11). In addition to the criteria provided in Table 11 for accurate diagnosis, the patient suspected of RHF must have at least two clinical signs suggestive of RHF (Table 12).

Hemodynamic criteria predictive of the development of RHF following LVAD placement are well studied. However, the studies varied by trial design and used differ- 


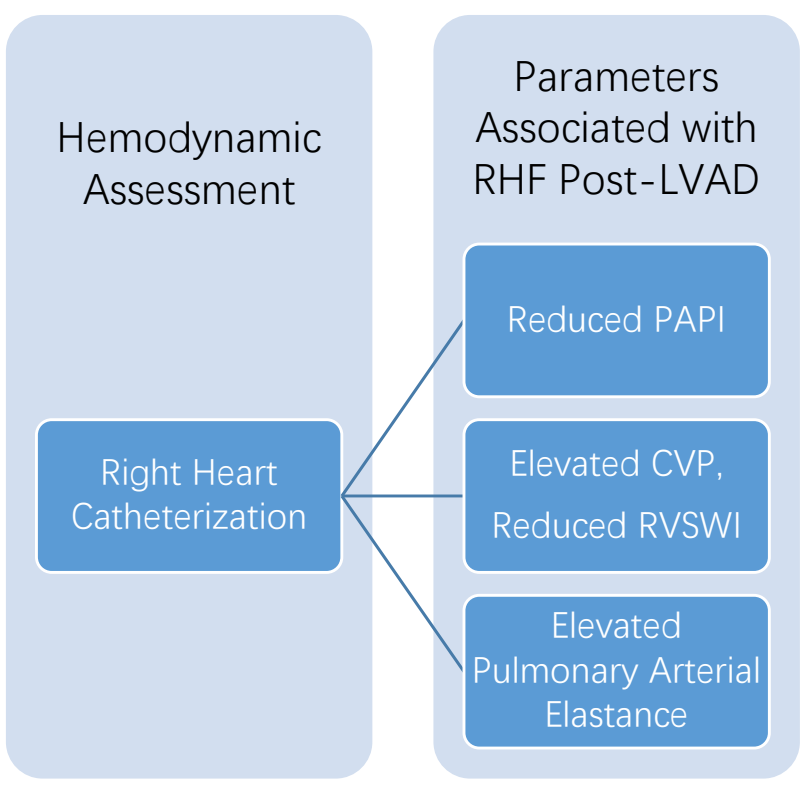

Fig. 3. Hemodynamic parameters associated with right heart failure post left ventricular assist device implantation. CVP, central venous pressure; PAPI, pulmonary artery pulsatility index; RVSWI, right ventricular stroke work index.

ent definitions. Kang et al. [42] reported that the PAPI score was an independent predictor of RHF and the need for RVAD support after LVAD implantation. In a 2017 systematic review and meta-analysis of observational studies, Bellavia et al. [44] found that elevated CVP and reduced RV stroke work index were the hemodynamic parameters most strongly associated with the development of RHF post LVAD implantation. A 2019 multicenter study of 375 patients by Muslem et al. [45] evaluated the relationship between RHC hemodynamic data within the preceding 30 days of LVAD implantation and investigated the relationship to RHF using the INTERMACS definition. The authors found that higher pulmonary arterial elastance (the ratio of systolic pulmonary artery pressure to stroke volume) was a significant predictor of severe RHF following LVAD implantation (Fig. 3) [45].

More importantly, RHF after LVAD implantation requiring RVAD support reduces overall survival to $50 \%$ at 1 year and increases morbidity. The current, simplified and more standardized definition for RHF post-LVAD, may potentially allow a more accurate assessment of the hemodynamic variables that need optimization to prevent postLVAD RHF.

\section{Conclusions}

For patients with advanced heart failure, RHC will remain an important standard of care for diagnostic and prognostic purposes as well as for long-term management.

\section{Author contributions}

Authors AA and JMC contributed equally. CYGM contributed substantially. Each author was involved in every step of the writing process.

\section{Ethics approval and consent to participate}

Not applicable.

\section{Acknowledgment}

Not applicable.

\section{Funding}

This research received no external funding.

\section{Conflict of interest}

The authors declare no conflict of interest.

\section{References}

[1] Meyer JA. Werner Forssmann and catheterization of the heart, 1929. The Annals of Thoracic Surgery. 1990; 49: 497-499.

[2] Chatterjee K. The Swan-Ganz Catheters: Past, Present, and Future. A viewpoint. Circulation. 2009; 119: 147-152.

[3] Swan HJ, Ganz W, Forrester J, Marcus H, Diamond G, Chonette D. Catheterization of the Heart in Man with Use of a FlowDirected Balloon-Tipped Catheter. New England Journal of Medicine. 1970; 283: 447-451.

[4] Borlaug BA, Kass DA. Invasive Hemodynamic Assessment in Heart Failure. Heart Failure Clinics. 2009; 5: 217-228.

[5] Feigenbaum H. Evolution of echocardiography. Circulation. 1996; 93: 1321-1327.

[6] Nishimura RA, Tajik AJ. Quantitative hemodynamics by Doppler echocardiography: a noninvasive alternative to cardiac catheterization. Progress in Cardiovascular Diseases. 1994; 36: 309-342.

[7] Temporelli PL, Scapellato F, Eleuteri E, Imparato A, Giannuzzi P. Doppler echocardiography in advanced systolic heart failure: a noninvasive alternative to Swan-Ganz catheter. Circulation. Heart Failure. 2010; 3: 387-394.

[8] Thibodeau JT, Drazner MH. The Role of the Clinical Examination in Patients with Heart Failure. JACC: Heart Failure. 2018; 6: 543-551.

[9] From AM, Lam CS, Pitta SR, Kumar PV, Balbissi KA, Booker $\mathrm{JD}$, et al. Bedside assessment of cardiac hemodynamics: the impact of noninvasive testing and examiner experience. The American Journal of Medicine. 2011; 124: 1051-1057.

[10] Drazner MH, Hamilton MA, Fonarow G, Creaser J, Flavell C, Stevenson LW. Relationship between right and left-sided filling pressures in 1000 patients with advanced heart failure. The Journal of Heart and Lung Transplantation. 1999; 18: 1126-1132.

[11] Binanay C, Califf RM, Hasselblad V, O'Connor CM, Shah MR, Sopko G, et al. Evaluation study of congestive heart failure and pulmonary artery catheterization effectiveness: the ESCAPE trial. The Journal of American Medical Association. 2005; 294: 1625-1633.

[12] Yancy CW, Jessup M, Bozkurt B, Butler J, Casey DE, Drazner MH, et al. 2013 ACCF/AHA guideline for the management of heart failure: a report of the American College of Cardiology Foundation/American Heart Association Task Force on Practice Guidelines. Journal of the American College of Cardiology. 2013; 62: e147-e239.

[13] McDonagh TA, Metra M, Adamo M, Gardner RS, Baumbach A, Böhm M, et al. 2021 ESC Guidelines for the diagnosis and treatment of acute and chronic heart failure. European Heart Journal. 2021; 42: 3599-3726.

[14] van Diepen S, Katz JN, Albert NM, Henry TD, Jacobs AK, Kapur NK, et al. Contemporary Management of Cardiogenic 
Shock: a Scientific Statement from the American Heart Association. Circulation. 2017; 136: e232-e268.

[15] Baran DA, Grines CL, Bailey S, Burkhoff D, Hall SA, Henry $\mathrm{TD}$, et al. SCAI clinical expert consensus statement on the classification of cardiogenic shock: This document was endorsed by the American College of Cardiology (ACC), the American Heart Association (AHA), the Society of Critical Care Medicine (SCCM), and the Society of Thoracic Surgeons (STS) in April 2019. Catheterization and Cardiovascular Interventions. 2019; 94: 29-37.

[16] Menon V, Slater JN, White HD, Sleeper LA, Cocke T, Hochman JS. Acute myocardial infarction complicated by systemic hypoperfusion without hypotension: report of the SHOCK trial registry. The American Journal of Medicine. 2000; 108: 374-380.

[17] Kapur NK, Esposito ML, Bader Y, Morine KJ, Kiernan MS, Pham DT, et al. Mechanical Circulatory Support Devices for Acute Right Ventricular Failure. Circulation. 2017; 136: 314326.

[18] Guerrero-Miranda CY, Hall SA. Cardiogenic Shock in Patients with Advanced Chronic Heart Failure. Methodist DeBakey Cardiovascular Journal. 2020; 16: 22-26.

[19] Basir MB, Kapur NK, Patel K, Salam MA, Schreiber T, Kaki A, et al. Improved Outcomes Associated with the use of Shock Protocols: Updates from the National Cardiogenic Shock Initiative. Catheterization and Cardiovascular Interventions. 2019; 93: 1173-1183.

[20] Tehrani BN, Truesdell AG, Sherwood MW, Desai S, Tran HA, Epps KC, et al. Standardized Team-Based Care for Cardiogenic Shock. Journal of the American College of Cardiology. 2019; 73: $1659-1669$

[21] Basir MB, Schreiber TL, Grines CL, Dixon SR, Moses JW, Maini BS, et al. Effect of Early Initiation of Mechanical Circulatory Support on Survival in Cardiogenic Shock. The American Journal of Cardiology. 2017; 119: 845-851.

[22] Sorajja P, Borlaug BA, Dimas VV, Fang JC, Forfia PR, Givertz $\mathrm{MM}$, et al. SCAI/HFSA clinical expert consensus document on the use of invasive hemodynamics for the diagnosis and management of cardiovascular disease. Catheterization and Cardiovascular Interventions. 2017; 89: E233-E247.

[23] Chantranuwat C, Blakey JD, Kobashigawa JA, Moriguchi JD, Laks H, Vassilakis ME, et al. Sudden, unexpected death in cardiac transplant recipients: an autopsy study. The Journal of Heart and Lung Transplantation. 2004; 23: 683-689.

[24] Bellettini M, Frea S, Pidello S, Boffini M, Boretto P, Gallone $\mathrm{G}$, et al. Pretransplant Right Ventricular Dysfunction is Associated with Increased Mortality after Heart Transplantation: a Hard Inheritance to Overcome. Journal of Cardiac Failure. 2021. (in press)

[25] Drazner MH, Velez-Martinez M, Ayers CR, Reimold SC, Thibodeau JT, Mishkin JD, et al. Relationship of right- to left-sided ventricular filling pressures in advanced heart failure: insights from the ESCAPE trial. Circulation. Heart Failure. 2013; 6: 264-270.

[26] Al-Omary MS, Sugito S, Boyle AJ, Sverdlov AL, Collins NJ. Pulmonary Hypertension Due to Left Heart Disease: Diagnosis, Pathophysiology, and Therapy. Hypertension. 2020; 75: 13971408.

[27] Galiè N, McLaughlin VV, Rubin LJ, Simonneau G. An overview of the 6th World Symposium on Pulmonary Hypertension. European Respiratory Journal. 2019; 53: 1802148.

[28] Vachiéry JL, Tedford RJ, Rosenkranz S, Palazzini M, Lang I, Guazzi M, et al. Pulmonary hypertension due to left heart disease. European Respiratory Journal. 2019; 53: 1801897.

[29] Taylor DO, Stehlik J, Edwards LB, Aurora P, Christie JD, Dobbels F, et al. Registry of the International Society for Heart and Lung Transplantation: Twenty-sixth Official Adult Heart Transplant Report-2009. The Journal of Heart and Lung Transplantation. 2009; 28: 1007-1022.
[30] Alam A, Milligan GP, Joseph SM. Reconsidering the Diagnostic Criteria of Right Ventricular Primary Graft Dysfunction. Journal of Cardiac Failure. 2020; 26: 985-986.

[31] Kobashigawa J, Zuckermann A, Macdonald P, Leprince P, Esmailian F, Luu M, et al. Report from a consensus conference on primary graft dysfunction after cardiac transplantation. The Journal of Heart and Lung Transplantation. 2014; 33: 327-340.

[32] Lim HS, Hsich E, Shah KB. International Society of Heart and Lung Transplantation position statement on the role of right heart catheterization in the management of heart transplant recipients. The Journal of Heart and Lung Transplantation. 2019; 38: 235238.

[33] Villavicencio MA, Larraín E, Larrea R, Peralta JP, Lim JS, Rojo $\mathrm{P}$, et al. Bridge to transplant or recovery in cardiogenic shock in a developing country. Asian Cardiovascular and Thoracic Annals. 2017; 25: 105-112.

[34] Mehra MR, Kobashigawa J, Starling R, Russell S, Uber PA Parameshwar $\mathrm{J}$, et al. Listing criteria for heart transplantation: International Society for Heart and Lung Transplantation guidelines for the care of cardiac transplant candidates-2006. The Journal of Heart and Lung Transplantation. 2006; 25: 1024 1042 .

[35] Deng MC, Eisen HJ, Mehra MR, Billingham M, Marboe CC, Berry G, et al. Noninvasive discrimination of rejection in cardiac allograft recipients using gene expression profiling. American Journal of Transplantation. 2006; 6: 150-160.

[36] Molina EJ, Shah P, Kiernan MS, Cornwell WK, Copeland H, Takeda K, et al. The Society of Thoracic Surgeons Intermacs 2020 Annual Report. The Annals of Thoracic Surgery. 2021; 111: 778-792.

[37] Bollano E, Andersson B, Hjalmarsson C, Dellgren G, Daka B, Karason K. Early post-transplant elevated pulmonary artery pressure predicts adverse outcome in cardiac recipients. International Journal of Cardiology. Heart \& Vasculature. 2020; 26: 100438.

[38] Molkentin JP, Nägele MP, Frank M, Sudano I, Enseleit F, Wilhelm MJ, et al. Prognostic value of mean pulmonary artery pressure in the stable phase after heart transplantation. European Journal of Cardio-Thoracic Surgery. 2017; 52: 775-780.

[39] Kormos RL, Antonides CFJ, Goldstein DJ, Cowger JA, Starling RC, Kirklin JK, et al. Updated definitions of adverse events for trials and registries of mechanical circulatory support: a consensus statement of the mechanical circulatory support academic research consortium. The Journal of Heart and Lung Transplantation. 2020; 39: 735-750.

[40] Pagani FD. Right Heart Failure after Left Ventricular Assist Device Placement: Medical and Surgical Management Considerations. Cardiology Clinics. 2020; 38: 227-238.

[41] Cowger JA, Molina EJ, Pagani FD. Intermacs: Evolving data capture to meet scientific needs. The Annals of Thoracic Surgery. 2021. (in press)

[42] Kang G, Ha R, Banerjee D. Pulmonary artery pulsatility index predicts right ventricular failure after left ventricular assist device implantation. The Journal of Heart and Lung Transplantation. 2016; 35: 67-73.

[43] Lim K, Choi JO, Yang JH, Park S, Kim SH, Kang J, et al. Cardiac Resynchronization Therapy Device Implantation in a Patient with Cardiogenic Shock under Percutaneous Mechanical Circulatory Support. Korean Circulation Journal. 2017; 47: 132-135.

[44] Bellavia D, Iacovoni A, Scardulla C, Moja L, Pilato M, Kushwaha SS, et al. Prediction of right ventricular failure after ventricular assist device implant: systematic review and metaanalysis of observational studies. European Journal of Heart Failure. 2017; 19: 926-946.

[45] Muslem R, Ong CS, Tomashitis B, Schultz J, Ramu B, Craig ML, et al. Pulmonary Arterial Elastance and INTERMACSDefined Right Heart Failure Following Left Ventricular Assist Device. Circulation. Heart Failure. 2019; 12: e005923. 